\title{
A randomised, double-blinded clinical study on the efficacy of multimedia presentation using an iPad for patient education of postoperative hip surgery patients in a public hospital in Singapore
}

Rachel-Kim Dallimore ${ }^{1}$, MSc, Marxengel Leonin Asinas-Tan ${ }^{2}$, MD, MPH, Daryl Chan ${ }^{1}$, DipPhty, Suharti Hussain ${ }^{1}$, BSc, Catherine Willett $^{1}$, MSc, Rahizan Zainuldin ${ }^{1}$, PhD

\begin{abstract}
INTRODUCTION This study compared patient satisfaction and recall of physiotherapy patient education among patients who had undergone hip surgery, with information presented via an iPad versus a standard paper booklet.

METHODS Patients who had undergone hip surgery joined and completed this single-centre study, which utilised a randomised parallel group design. They were randomly allocated to either Group A (received information on hip surgery physiotherapy via an iPad) or Group B (received the same information via a paper booklet). The participants were blinded to the intervention received by the other group and the testers were blinded to the intervention received by the participants. The interventions were carried out during the patients' first four postoperative physiotherapy sessions. The outcome measures were recorded using pre-validated questionnaires.

RESULTS A total of 42 participants (mean age $70 \pm 12$ years) were recruited. After the intervention, patients in both groups had improved recall of the information presented during patient education. However, the patients in Group A had a significantly better recall score than those in Group B $(4.0$ points higher, $p<0.001)$. The level of patient satisfaction was also significantly higher in Group A than in Group B (8.5 points higher, $p<0.001)$.

CONCLUSION While the use of an iPad and a paper booklet both had positive outcomes for patient recall and satisfaction, the use of an iPad was found to be more effective at improving patient satisfaction and recall of physiotherapy patient education in the present study.
\end{abstract}

Keywords: hip surgery, iPad, patient education, physiotherapy

\section{INTRODUCTION}

Patient education, defined as the transfer of health-related knowledge and skills from a healthcare professional to a patient, has been identified as an important component in many health promotion and disease management programmes. ${ }^{(1,2)}$ There is an increasing emphasis on engaging and empowering patients in their own therapy, whether it is in the goal-setting process, in disease management monitoring, or simply by helping patients make informed decisions about their treatment. A patient-centred approach has recognised benefits, including greater adherence to interventions and greater patient satisfaction. ${ }^{(3,4)}$ Patient education is an important part of rehabilitation for patients following hip surgery. During patient education, the patients and/or their caregivers are given key information about how they can care for themselves/the patient after surgery (e.g. precautions to take and hip exercises that can be done). Patient education is often delivered by healthcare professionals via the use of information booklets, which are not costly to produce. ${ }^{(5)}$

In the last decade, we have seen the introduction of new technology and its ability to transform education, which points to the potential of technology to enhance patient learning and patient care. ${ }^{(6)}$ Since the release of the iPad (Apple Inc, Cupertino, CA, USA) in 2010, it has proven to be a useful tool for both the general public and medical practitioners; in the medical arena, this has resulted in the rapid development of applications designed for medical use, such as those for enhancing inpatient education. ${ }^{(7,8)}$ The iPad's user-friendly interface and its ability to provide interactive platforms are features that make it suitable as a tool for enhanced learning. Its portability means that it can be used by the bedside, and its large screen enables educational images and interactive multimedia to be clearly displayed.

Patient education is often limited by language barriers. A study by Brock and Smith ${ }^{(9)}$ concluded that more could be done to explore the development of educational tools that are linguistically appropriate for diverse patient populations. The current patient education booklets used in the centre in which the present study was conducted are only available in English. Even though the text is accompanied by pictures, these booklets may not be suitable for use in the elderly population. This is because although most Singaporeans are bilingual in English and a native language, commonly Mandarin (36.3\%), Malay (13.3\%) or Tamil $(4.4 \%)$, many elderly individuals are more fluent in their native language. ${ }^{(10)}$ The lack of information in native languages may result in patients having reduced access to information and lower rates of patient engagement, which may contribute to patients feeling anxious and dissatisfied, and having poor recall of the

${ }^{1}$ Rehabilitation Department, ${ }^{2}$ Emergency Medicine Department, Ng Teng Fong General Hospital, Jurong Health Services, Singapore

Correspondence: Ms Rachel-Kim Dallimore, Principal Physiotherapist, Rehabilitation Department, Ng Teng Fong General Hospital, 1 Jurong East Street 21 , Singapore 609606. rachel_dallimore@nuhs.edu.sg 
knowledge needed. ${ }^{(11)}$ Therefore, it is paramount that efforts be made to improve the method of educating patients on potentially complex information, especially if there is a language barrier, which may be the case in multiracial Singapore. Using iPads to deliver information may help to eradicate the language barrier, as the educational material can be programmed to be available in multiple languages in a single interface and device.

The efficacy of multimedia-based tools versus paper-based tools for hip surgery patient education has yet to be investigated in Singapore. Postoperative therapy instructions can be complex, especially instructions on how to perform the rehabilitation exercises correctly. There is a lack of studies investigating the use of iPads for educating patients who have undergone hip surgery. Thus, this study aimed to determine whether physiotherapy patient education, delivered using iPad applications, was effective in eliciting greater patient recall and satisfaction as compared to patient education delivered using a paper-based booklet, among a cohort of patients who had undergone hip surgery.

\section{METHODS}

This was a single-centre study that utilised a randomised parallel group design. We recruited patients who underwent hip surgery and were admitted to Alexandra Hospital, Singapore, between March 2014 and October 2014. In-house grant funding was used to supply the equipment used in the study, but the institution had no direct involvement in the study. Written consent was obtained from all participants and ethical approval was given by the Domain Specific Review Board of the National Healthcare Group, Singapore. Patients who had undergone elective total hip replacement, hemiarthroplasty, or hip surgeries using cancellous screws, dynamic hip screws or proximal femoral nail anti-rotation were included in the study. Participants were excluded from the study if they had postoperative complications (e.g. neurological, cardiovascular and/or other unstable medical conditions that would preclude exercising during the physiotherapy sessions); were premorbidly non-ambulatory or bedbound; had a history of previous hip surgery, mental instability or cognitive impairment; and/or were unable to speak English, Mandarin or Malay.

Block randomisation was used to allocate participants into either Group A or Group B. Participants in Group A received information on hip surgery physiotherapy via an iPad Air, while participants in Group B received the same information via a standard paper booklet. In order to avoid selection bias, the blocking system (including the block sizes) was not revealed to the investigators who were responsible for allocating patients to the groups. ${ }^{(12,13)}$

The contents and wording of the patient information were the same for both the iPad and paper booklet. The information presented included evidence-based exercises that were specific to hip surgery, hip precaution advice, and general advice on how to transfer safely on and off a bed and chair. Although the contents and wording of the information were identical for both the iPad and booklet, the contents on the iPad were presented in a multimedia format (i.e. videos were used instead of static images). These videos were available in multiple languages
(English, Mandarin and Malay), and had corresponding audio format and subtitles. The paper booklets were A5 in size, written in English and had pictures to augment the contents. In addition to patient education, both groups of participants also received four 30-minute sessions of standard physiotherapy treatment. Each session included demonstrations and practice of hip exercises (e.g. open kinetic exercises for non-weight-bearing participants and closed kinetic exercises for full or partial weight-bearing participants), mobilisation, gait re-education and postoperative chest care. The fourth physiotherapy session was chosen to be the testing session, as this was the average inpatient length of stay for patients following hip surgery in the institution.

To minimise bias, the same team of orthopaedic physiotherapists, who were blinded to the patient groups, were employed throughout the study. The participants were also blinded to the type of intervention (i.e. patient education via iPad or paper booklet) given to the other group. Administration of the intervention, which included educating the relevant participants on how to use the iPad, was done by therapy assistants in order to keep the physiotherapists blinded to the participant groups.

Data collection ceased following the fourth physiotherapy session. After the session, the participants in Group A were given the same booklet that was used by participants in Group B in order to resume care as part of the institution's standard provision of patient education material. Standard physiotherapy sessions were continued for the study participants until they were discharged from the institution.

The outcome measures for this study were patient satisfaction (of patient education received) and patient recall (of patient education contents received via the iPad or paper booklet). Both of these outcomes were measured using pre-validated questionnaires that were adapted from the World Health Organization's Quality of Life Questionnaire (Appendices 1 \& 2). ${ }^{(14)}$ Patient satisfaction was evaluated using a pre-validated patient satisfaction questionnaire, which was translated to English, Mandarin and Malay. The questionnaire was given to all participants after their fourth physiotherapy session. Each item was measured using a five-point Likert scale (where 1 is the most negative response and 5 is the most positive); the maximum total score of all the items was 30 points. All tests were administered by staff who were blinded to the intervention that was received by the participants.

Patient recall was assessed using a questionnaire that measured the extent of knowledge gained. The questionnaire contained ten questions and the patient's score was calculated based on the number of correctly answered questions; the maximum score was 10. A pre-test, using a pre-validated questionnaire that was translated to English, Mandarin and Malay, was performed on the participants of both groups before their first physiotherapy session. This was done to measure the participants' baseline knowledge of the material that would be taught during patient education. The pre-test scores were predicted to be low, since no physiotherapy education or intervention had taken place at this point. The same language questionnaire was administered again after the four physiotherapy sessions. 


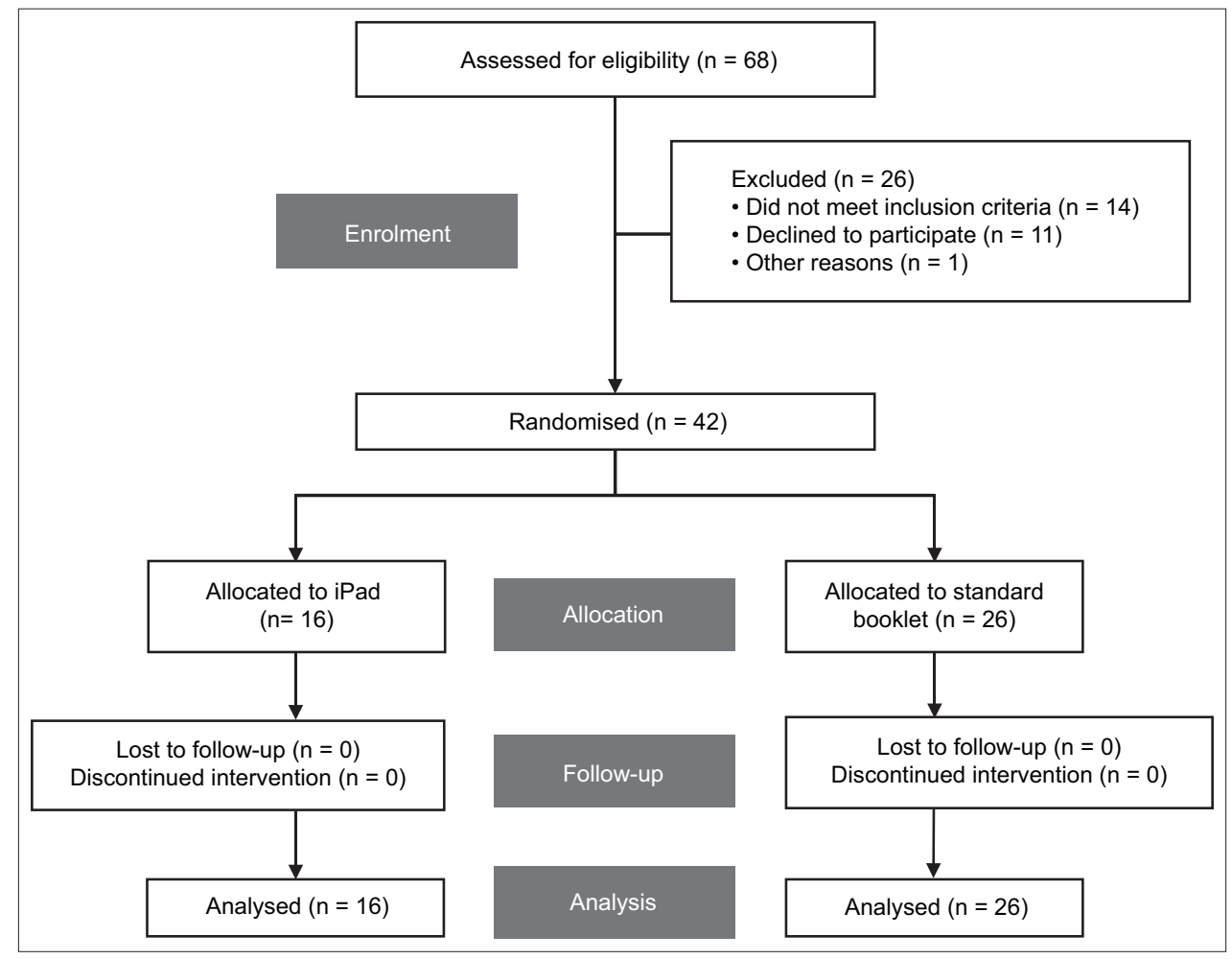

Fig. 1 CONSORT chart shows the phases (enrolment, allocation, follow-up and analysis) of the present study.

The outcome measures (i.e. patient satisfaction and patient recall scores) were presented as group mean \pm standard deviation, unless otherwise stated. Statistician sample size calculation concluded that a sample size of 42 participants was required. Paired $t$-test was used to compare the patient recall scores before and after the intervention within the groups, while independent $t$-test was used to compare the patient satisfaction scores and patient recall scores between groups. Pearson correlation was used to evaluate plausible correlations between the variables. The confidence level was set at $95 \%$ and a p-value $<0.05$ was deemed statistically significant. Statistical analysis was done using IBM SPSS Statistics for Windows version 21 (IBM Corp, Armonk, NY, USA) and ' $R$ ' software (The R Foundation, Auckland, New Zealand).

\section{RESULTS}

A total of 42 participants were recruited for this study. They were divided into two groups using block randomisation - 16 participants were placed in Group A (received physiotherapy patient education on hip surgery via an iPad), while 26 participants were placed in Group B (received physiotherapy patient education on hip surgery via a paper booklet). None of the participants withdrew from the study (Fig. 1).

Table I shows the characteristics of the participants according to their groups. Demographic variables, such as age, gender, ethnicity, nationality, highest educational attainment, first language and experience with computers, were similar between the two groups. There was also no significant difference in the mean scores of the participants in the pre-test that was performed before the participants received their first physiotherapy session (Group A: $0.13 \pm 0.34$ vs. Group B:
$0.15 \pm 0.46$, mean difference: $-0.02 ; 95 \%$ confidence interval [CI] -0.30 to $0.24, p=0.83$ ).

After the intervention (i.e. patient education using either an iPad or a paper booklet), there were significant improvements in the patient recall scores of both groups. For Group A, the mean patient recall score after the intervention was $6.4 \pm 1.6$ (mean increase 6.3 points; 95\% Cl 5.4-7.2, p < 0.001). For Group B, the mean patient recall score after the intervention was $2.4 \pm 1.3$ (mean increase 2.3 points; $95 \% \mathrm{Cl} 1.8-2.7, \mathrm{p}<0.001$ ). The improvement in mean patient recall score was significantly greater for Group A than for Group B (mean difference of 4.0, 95\% Cl $3.16-4.95, \mathrm{p}<0.001)$.

In terms of patient satisfaction, the participants in Group A reported significantly higher satisfaction levels than those in Group B. The mean patient satisfaction score of the participants in Group A was $25.1 \pm 4.3$, while that of the participants in Group B was $16.6 \pm 7.4$ (mean difference of 8.5 ; 95\% Cl 4.8-12.1, $\mathrm{p}<0.001)$.

\section{DISCUSSION}

The results of the present study showed that physiotherapy patient education using both iPads and paper booklets resulted in improved patient recall. However, the improvement in patient recall scores was significantly higher for those who received patient education via the use of an iPad than for those who received patient education via the use of a paper booklet. The mean patient satisfaction score was also significantly higher in the group that received patient education via the use of an iPad versus those who used a paper booklet. These findings suggest that the use of iPads for physiotherapy patient education for patients who have undergone hip surgery may be a more effective method 
Table I. Demographic characteristics of the participants $(n=42)$.

\begin{tabular}{|c|c|c|c|}
\hline \multirow[t]{2}{*}{ Variable } & \multicolumn{2}{|c|}{ No. (\%) } & \multirow[t]{2}{*}{ p-value } \\
\hline & $\begin{array}{l}\text { Group A } \\
(n=16)\end{array}$ & $\begin{array}{l}\text { Group B } \\
(n=26)\end{array}$ & \\
\hline Age* (yr) $^{*}$ & $68 \pm 13$ & $72 \pm 12$ & 0.386 \\
\hline Gender & & & 0.158 \\
\hline Male & $7(43.8)$ & $5(19.2)$ & \\
\hline Female & $9(56.3)$ & $21(80.8)$ & \\
\hline Ethnicity & & & 0.743 \\
\hline Chinese & $12(75.0)$ & $22(84.6)$ & \\
\hline Malay & $3(18.8)$ & $3(11.5)$ & \\
\hline Indian & $1(6.3)$ & $1(3.8)$ & \\
\hline Nationality & & & 0.402 \\
\hline Singaporean & $14(87.5)$ & $25(96.2)$ & \\
\hline Others & $2(12.5)$ & $1(3.8)$ & \\
\hline $\begin{array}{l}\text { Highest educational } \\
\text { attainment }\end{array}$ & & & 0.173 \\
\hline No formal education & $3(18.8)$ & $10(38.5)$ & \\
\hline Primary & $8(50.0)$ & $5(19.2)$ & \\
\hline Secondary & $4(25.0)$ & $7(26.9)$ & \\
\hline Tertiary & $1(6.3)$ & $4(15.4)$ & \\
\hline First language & & & 0.678 \\
\hline English & $4(25.0)$ & $9(34.6)$ & \\
\hline Mandarin & $8(50.0)$ & $13(50.0)$ & \\
\hline Malay & $4(25.0)$ & $4(15.4)$ & \\
\hline Experience with computers & & & 0.222 \\
\hline Yes & $15(93.8)$ & $20(76.9)$ & \\
\hline No & $1(6.3)$ & $6(23.1)$ & \\
\hline
\end{tabular}

*Data presented as mean \pm standard deviation.

of improving patient recall and satisfaction, as compared to the current paper booklets. The findings of the present study also suggest that elderly patients (mean age $70 \pm 12$ years) were able to use an iPad effectively.

A plausible reason for these findings is that the paper booklets that are currently used in our hospital were designed to provide generalised information to a wide audience in a single language. On the other hand, the use of the iPad allowed patient education to be tailored (available options included translation into another language, enlargement of images and the use of sound) and this may have helped to enhance patient understanding. The iPad can also be used as a dynamic learning tool, empowering patients to take control of their own learning. This could have made the patient education experience more interactive and memorable for the patient. ${ }^{(5,6,9,15)}$

Patient satisfaction continues to receive attention as an outcome measure of therapy, as quality of care and patient satisfaction synergistically influence the outcome of therapy. ${ }^{(16)}$ Patient satisfaction is a measure of the quality of care received, as well as an indication of the likelihood of patient compliance with treatment. ${ }^{(3,17)}$ Goldstein et $\mathrm{al}^{(16)}$ stated that the reliability and validity of measurements obtained from questionnaires measuring patient satisfaction are influenced by the patient's ability to recall aspects of the treatment process; hence, a patient recall component was also measured in the present study. Since both the patient recall and patient satisfaction scores for the group that received education via iPads were significantly higher than for the group that received education via paper booklets, it is reasonable to assume that patient education delivered via iPads could be an acceptable standard for patients who have undergone hip surgery.

The findings of the present study are in agreement with those of previous research, which showed that computer-based education is effective for patients of all ages and that the use of audiovisual materials can enhance learning and lead to improved treatment outcomes. ${ }^{(2,5,9,15)}$ Our results also support the findings of Vawdrey et al's study, ${ }^{(11)}$ which showed that patients were generally excited about the ability of their tablet computer application to provide patient-specific health information, as the participants who received patient education via the iPad had significantly higher patient satisfaction scores than those who received patient education via a paper booklet.

The present study was not without limitations. Firstly, the study relied on the assumption that improvements in patient recall scores were attributed to the interventions used in the study. Other external teaching materials, such as the patient's own means of accessing the Internet, were not considered. Furthermore, we recognise that the participants' own motivation in learning could have contributed to the patient recall scores. During the study, we did not monitor the precise amount of time that the participants spent using the iPad or paper booklet, or the pages and videos they read or watched.

Additionally, while the intention was to allocate an almost equal number of participants to each group, the use of random block sizes to prevent selection bias resulted in 16 participants being allocated to Group A (i.e. received patient education via an iPad) and 26 participants being allocated to Group B (i.e. received patient education via a paper booklet). Further recruitment of participants beyond that of the sample size was not possible due to the scarcity of patients who fulfilled the study's inclusion criteria. Moreover, forcing equal group sizes could have potentially harmed the unpredictability of treatment assignments and negated the effect of the randomisation technique.

Finally, we also did not measure improvements in the practice of information gained, as it was beyond the scope of the study. Future studies evaluating how patients process the information they have learnt and whether they are able to translate the knowledge gained into action (i.e. whether they are able to perform the hip exercises and other instructions provided in the patient education) would be beneficial. ${ }^{(2)}$

Although different surgery types (i.e. elective and traumatic) were included in the present study, caution is warranted when generalising the findings of this study to other populations of patients who have undergone hip surgery; further research with larger sample sizes is needed for that purpose. Future research on patient education for other medical conditions and for single surgery types is also warranted.

To conclude, the present study showed that while the use of iPads and paper booklets had positive effects on patient recall and patient satisfaction, the use of iPads resulted in significantly 
better patient recall and patient satisfaction scores. In addition, the positive satisfaction scores of the participants in this group showed that the use of modern technology for patient education was effective even among elderly patients. With the growing use of information technology in the healthcare industry, demands for portability, easy access, and up-to-date information for patients and their caregivers are fast becoming a service provision requirement. As patient education is a major component of physiotherapy, it has the potential to affect therapy outcomes, including the patient's perception of the quality of therapy. Therefore, patient education should be designed to cater to the needs of the patients and their caregivers. For instance, issues such as language barriers should be addressed, as it has the potential to improve therapy outcomes.

\section{ACKNOWLEDGEMENT}

The authors would like to thank Shawn Ngiam, Ng Teng Fong General Hospital, for his contributions as a multimedia specialist.

\section{REFERENCES}

1. Lewis D. Computer-based applications to patient education: a review of the literature. J Am Med Inform Assoc 1999; 6:272-82.

2. Lewis D. Computers in patient education. Comput Inform Nurs 2003; 21:88-96

3. Beattie P, Turner C, Dowda M, Michener L, Nelson R. The MedRisk Instrument for Measuring Patient Satisfaction with Physical Therapy Care: a psychometric analysis. J Orthop Sports Phys Ther 2005; 35:24-32.
4. Dreeben-Irimia O. Patient Education in Rehabilitation. Massachusetts: Jones and Bartlett Learning; 2010.

5. Hill A, McPhail S, Hoffmann T, et al. A randomized trial comparing digital video disc with written delivery of falls prevention education for older patients in hospital. J Am Geriatr Soc 2009; 57:1458-63.

6. Wallace S, Clark M, White J. 'It's on my iPhone': attitudes to the use of mobile computing devices in medical education, a mixed-methods study. BMJ Open $2012 ; 2$.

7. Franko OI, Bhola S. iPad apps for orthopedic surgeons. Orthopedics 2011; 34:978-81.

8. Berger E. The iPad: gadget of medical godsend? Ann Emerg Med 2010; 56:A21-2.

9. Brock TP, Smith SR. Using digital videos displayed on personal digital assistants (PDAs) to enhance patient education in clinical settings. Int J Med Inform 2007; 76:829-35.

10. Singapore Demographics Profile 2014. In: Index Mundi [online]. Available at: http://www.indexmundi.com/singapore/demographics_profile.html. Accessed March 9, 2014.

11. Vawdrey DK, Wilcox LG, Collins SA, et al. A tablet computer application for patients to participate in their hospital care. AMIA Annu Symp Proc 2011; 2011:1428-35.

12. Schulz KF, Grimes DA. Unequal group sizes in randomised trials: guarding against guessing. Lancet 2002; 359:966-70.

13. Dumville JC, Hahn S, Miles JN, Torgerson DJ. The use of unequal randomisation ratios in clinical trials: a review. Contemp Clin Trials 2006; 27:1-12.

14. World Health Organization. Quality of Life (WHOQOL) - BREF. Available at: http://www.who.int/substance_abuse/research_tools/en/english_whoqol.pdf. Accessed January 5, 2014.

15. Ng YY, Tam SF. Evaluating the effectiveness of an interactive multimedia computer-based patient education program in cardiac rehabilitation. Hong Kong Med J 2006; 12(Suppl 1):S17-9.

16. Goldstein MS, Elliott SD, Guccione AA. The development of an instrument to measure satisfaction with physical therapy. Phys Ther 2000; 80:853-63.

17. Wensing M, Elwyn G. Methods for incorporating patients' views in health care. BMJ 2003; 326:877-9. 


\section{APPENDIX 1}

Pre- and post-therapy recall questionnaire (English)

\section{ASSESSMENT OF RECALL}

1. To complete the Heel Slide exercise, you should:
a) Sit upright and slowly slide your heel from left to right
b) Lie down and slide your heel slowly towards your buttock and slowly straighten
c) Lie down and slide your heel in a circular motion
d) I don't know

2. To complete the Straight Leg Raise exercise, you should lie with your knees straight and raise one leg while maintaining the straight knee. You should hold this pose for:
a) 2-3 seconds
b) 1 minute
c) 5-10 seconds
d) I don't know

3. To complete the Hip Abduction in Lying exercise, you should:
a) Lie with your knees bent and gently lift your leg up and down
b) Lie on your front and bring your heels to your buttock
c) Lie with your knees straight and gently bring your leg out to the side and back again
d) I don't know

4. To complete the Static Gluteal exercise, you should:
a) Lie with your knees straight and squeeze your buttock muscles together
b) Lie with your knees bent and squeeze your thigh muscles together
c) Lie with your knees bent and squeeze your buttock muscles together
d) I don't know

5. To complete the Static Quadriceps exercise, you should lie with your knees straight and squeeze the muscles in the front of your thigh for:
a) 5-10 seconds
b) 30 seconds
c) 2 minutes
d) I don't know

6. To complete the Inner Range Quadriceps exercise, you should place a rolled towel/pillow under you knee and try to:
a) Press the knee down to the bed
b) Lift your heel off the bed
c) Press the ankle down to the bed
d) I don't know

7. To complete the Knee Bending and Straightening in Sitting exercise, you should sit in a chair and straighten your knee for 5-10 seconds. This exercise should be done:
a) One leg at a time
b) Both legs at the same time
c) Raise both arms and legs at the same time
d) I don't know

8. To complete the Ankle Pump exercise, you should move your ankle up and down for:
a) 10 times/day
b) 20 times/hour
c) 10 times/hour
d) I don't know

9. To complete the Deep Breathing exercise, you should:
a) Breathe in through your nose and breathe out through your mouth slowly
b) Breathe in and hold your breath for 1 minute
c) Breathe in and out very rapidly
d) I don't know

10. Following hip surgery, the best chair for you to sit in is:
a) A low, plastic stool
b) A firm chair with arm rest and back rest
c) The floor
d) I don't know 


\section{APPENDIX 2}

Post-therapy satisfaction questionnaire (English)

\section{PATIENT SATISFACTION}

Thank you for taking the time to complete this survey! Your feedback is extremely important to us. All answers and comments will be kept strictly confidential.

The following questions ask about your overall satisfaction level during your stay in Alexandra Hospital.

\begin{tabular}{|c|c|c|c|c|c|}
\hline & \multicolumn{5}{|c|}{ (Please circle the number) } \\
\hline & $\begin{array}{c}\text { Very } \\
\text { dissatisfied }\end{array}$ & Dissatisfied & $\begin{array}{l}\text { Neither satisfied } \\
\text { nor dissatisfied }\end{array}$ & Satisfied & $\begin{array}{l}\text { Very } \\
\text { satisfied }\end{array}$ \\
\hline $\begin{array}{l}1 \text { How would you rate your overall satisfaction with } \\
\text { physiotherapy services? }\end{array}$ & 1 & 2 & 3 & 4 & 5 \\
\hline $\begin{array}{l}2 \text { How satisfied are you with the patient education } \\
\text { material provided? }\end{array}$ & 1 & 2 & 3 & 4 & 5 \\
\hline $\begin{array}{l}3 \text { How satisfied are you with your ability to perform } \\
\text { the exercises taught? }\end{array}$ & 1 & 2 & 3 & 4 & 5 \\
\hline
\end{tabular}

The following questions refer to the patient education material provided to you.

\begin{tabular}{|c|c|c|c|c|c|c|}
\hline & & \multicolumn{5}{|c|}{ (Please circle the number) } \\
\hline & & Not at all & A little & $\begin{array}{l}\text { A moderate } \\
\text { amount }\end{array}$ & $\begin{array}{l}\text { Very } \\
\text { much }\end{array}$ & $\begin{array}{l}\text { An extreme } \\
\text { amount }\end{array}$ \\
\hline & $\begin{array}{l}\text { To what extent did the patient education material } \\
\text { help your understanding of the exercises taught? }\end{array}$ & 1 & 2 & 3 & 4 & 5 \\
\hline 5 & $\begin{array}{l}\text { To what extent did the patient education material } \\
\text { assist your ability to perform the exercises taught? }\end{array}$ & 1 & 2 & 3 & 4 & 5 \\
\hline 6 & $\begin{array}{l}\text { To what extent did the patient education material } \\
\text { help you remember the exercises taught? }\end{array}$ & 1 & 2 & 3 & 4 & 5 \\
\hline
\end{tabular}

